\title{
Food deprivation and free-operant avoidance in the pigeon*
}

\author{
PATRICK GRIFFIN, H. D. MEDEARIS \\ and \\ WILLIAM R. HUGHES \\ University of Alabama, University, Ala. 35486
}

Two pigeons were trained with a free-operant avoidance schedule requiring a treadle response. Subsequent reduction in body weight to $80 \%$ increased the normally low shock rate, especially shock programmed by the response-shock interval. Ninety percent body weight resulted in a similar but, generally, less pronounced effect. For one $S$, response rate was an increasing function of body weight.

Davidson (1971) reported, in general, an increase in free-operant (Sidman) avoidance shock rate in marmosets when free-feeding body weight was reduced to $80 \%$. Response rate also declined but the effect was less consistent. Leander (1973, Experiment I) reported similar effects in rats. In general, shock and response rates were increasing and decreasing functions, respectively, of decrement in body weight. The present experiment investigated the repeatability of the avoidance-deprivation function in another species, viz., pigeons.

\section{METHOD}

\section{Subjects and Apparatus}

S P1 was naive and P2 had a history of auditory discrimination training but was naive with respect to electric shock and the treadle response. Both Ss were adult male Silver King pigeons, maintained with water and grit freely available in individual home cages.

The experimental chamber measured $30.5 \times 33.0 \times 38.1 \mathrm{~cm}$, was constructed of $1.9-\mathrm{cm}$ plywood, covered with acoustical tile, and equipped with a fan that provided masking noise and ventilation. One wall served as the response panel. A $7.6 \times 8.9 \mathrm{~cm}$ Plexiglas treadle (after Smith \& Keller, 1970) covered with hardware cloth was horizontally centered on the response panel, $5.7 \mathrm{~cm}$ above the chamber floor, with the $8.9-\mathrm{cm}$ edges parallel to the panel. The treadle formed a 45-deg angle with the floor, and depression with a force of $80 \mathrm{~g}(.79 \mathrm{~N})$ closed a microswitch and defined the response. Five centimeters either side of panel midline and $2.9 \mathrm{~cm}$ above the chamber floor was a 2.5-cm-diam translucent disk. These disks could be illuminated from behind the panel by 7-W 110-V ac white lights. Auditory feedback for all responses during a session was provided by a $28-\mathrm{V}$ dc relay behind the response panel. The experimental chamber was isolated from electromechanical control and recording equipment.

Electric shock was delivered through 20-ga Nichrome implanted electrodes (Azrin, 1959). Shock was a 250-msec pulse of $60-\mathrm{V}$ ac, $60 \mathrm{~Hz}$, delivered through $10 \mathrm{Kohms}$ resistance in series with $\mathrm{S}$.

*This article is sponsored by A. A. Baumeister, who takes full editorial responsibility. Reprints may be obtained from the first author, Department of Psychology, University of Alabama, University, Alabama 35486.

\section{Procedure}

No shaping procedure was used. Both Ss were exposed directly to a free-operant (Sidman) avoidance schedule with response-shock intervals (RS) of $30 \mathrm{sec}$ and shock-shock intervals (SS) of 10 sec. That is, once shock occurred, another shock was due $10 \mathrm{sec}$ later unless a response intervened. Each response postponed shock for $30 \mathrm{sec}$. Sessions were $90 \mathrm{~min}$ in duration, with the beginning and termination occasioned by the onset and offset, respectively, of the white chamber lights. All sessions began with an RS interval.

Table 1 summarizes the subsequent food-deprivation conditions. In all cases, percent body weight was based upon the mean weight for the last six sessions of the preceding free-feeding condition. During all deprivation conditions, body weight was maintained $\pm 2 \%$ of the required value by controlled feeding within $30 \mathrm{sec}$ following session completion. The numbers in parentheses in Table 1 indicate the number of sessions intervening between successive conditions, i.e., sessions required for body weight adjustment.

\section{RESULTS}

Performance for both Ss in terms of shock and response rates is illustrated in Fig. 1 for the last six sessions in each free-feeding condition and for the 18 sessions in each deprivation condition. Sessions during transitions in body weight between conditions are not shown.

Following an initial spike, $80 \%$ deprivation maintained performance, with a fivefold increase in shock rate over the free-feeding level for P1. Ninety percent deprivation resulted in approximately double the free-feeding shock rate. For the latter condition, however, the dominant effect was an increase in the upper range of shock rate, and there was considerable overlap with the free-feeding condition shock rates. Following the second free-feeding condition, reduction to $90 \%$ body weight again increased shock rate. Further reduction to $80 \%$, however, did not consistently increase shock rate above the $90 \%$ level. Response rate tended to decrease under deprivation, with the largest decrement occurring during the $80 \%$ condition. However, when body weight was increased from $80 \%$ to $90 \%$, response

Table 1

Sequence of Experimental Conditions

\begin{tabular}{lllll}
\hline & \multicolumn{4}{c}{ Number of Sessions } \\
\cline { 2 - 5 } Condition & \multicolumn{2}{c}{ S P1 } & \multicolumn{2}{c}{ S P2 } \\
\hline Free Feed & & 22 & & 65 \\
$80 \%$ & $(13)$ & 18 & $(14)$ & 18 \\
$90 \%$ & $(8)$ & 18 & $(9)$ & 18 \\
Free Feed & & 42 & & 42 \\
$90 \%$ & $(2)$ & 18 & $(2)$ & 18 \\
$80 \%$ & $(3)$ & 18 & $(5)$ & 18 \\
\hline
\end{tabular}




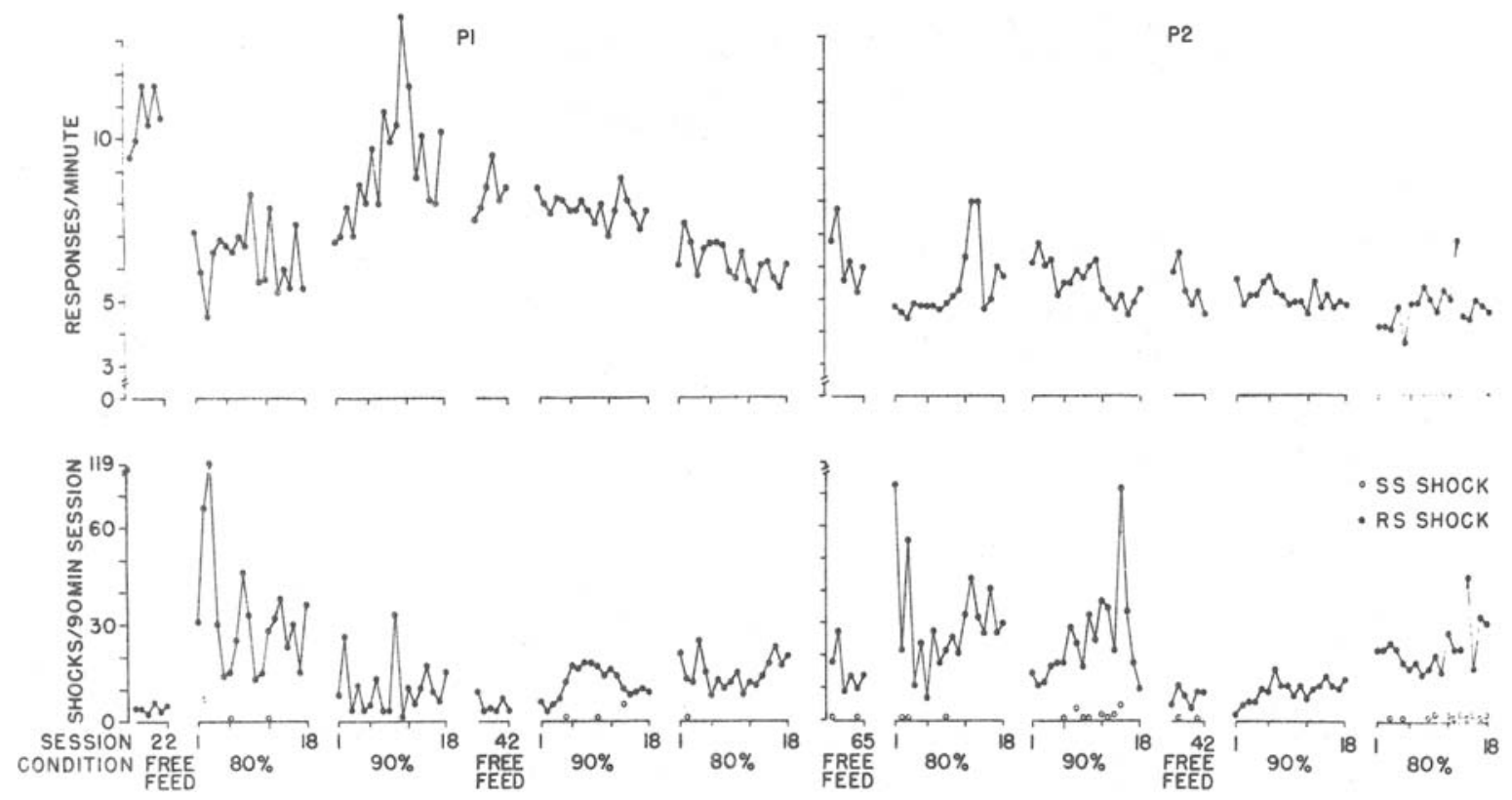

Fig. 1. Response and shock rates during the final six sessions of each free-feeding condition and throughout subsequent deprivation conditions.

rate temporarily exceeded the preceding free-feeding baseline.

For $\mathrm{P} 2$ the initial reduction to $80 \%$ body weight increased shock rate somewhat, with considerable overlap with the free-feeding condition data. Aside from the initial sessions, the increase in body weight to $90 \%$ did not substantially alter this pattern. The second sequence of conditions, however, resulted in a slight increase in shock rate for the $90 \%$ condition and, under $80 \%$ deprivation, rate was consistently above the free-feeding and, in most cases, the $90 \%$ levels. Response rate was not consistently related to deprivation conditions. Noticeable decrements in responding occurred only during the first 11 sessions of the first exposure to $80 \%$ deprivation and during the initial five sessions of the second exposure.

For both Ss, effects upon shock rate were reflected in RS shock. Rate of SS shock was usually zero; however, slight but consistent increments occurred for P2.

\section{DISCUSSION}

The essential absence of SS shocks and low RS shock rate under the present free-feeding conditions are consistent with other results using pigeons, a treadle response, and similar schedule details (e.g., Smith \& Keller, 1970). Deprivation, however, tended to increase shock rate, with the effect almost entirely limited to RS shock. For one $S$, response rate also consistently decreased under deprivation.

These data are generally consistent with those reported for rats (Leander, 1973) and marmosets (Davidson, 1971). Whether the latter effects were limited to RS shock, however, cannot be determined from the reports. The increase in shock rate variability under deprivation in the present case is also congruent with the Leander data.

The aggregate nature of the response rate measure hinders interpretation of the inconsistency of effect. A more informative analysis would ascertain for individual Ss: (1) the effects of deprivation upon the interresponse time (IRT) distribution and (2) the nature of postshock responding under sated and deprived conditions. These data would indicate which IRT classes are affected and the contribution of the increment in shock rate to response rate via postshock response bursts.

\section{REFERENCES}

Azrin, N. H. A technique for delivering shock to pigeons. Journal of the Experimental Analysis of Behavior, 1959, 2, 161-163. Davidson, R. S. Effects of food deprivation on free-operant avoidance. Psychological Reports, 1971, 29, 1019-1022.

Leander, J. D. Effects of food deprivation on free-operant avoidance behavior. Journal of the Experimental Analysis of Behavior, 1973, 19, 17-24.

Smith, R. F., \& Keller, F. R. Free-operant avoidance in the pigeon using a treadle response. Journal of the Experimental Analysis of Behavior, 1970, 13, 211-214.

(Received for publication March 15, 1973.) 